Check for updates

Cite this: RSC Adv., 2019, 9, 13631

Received 5th March 2019 Accepted 17th April 2019

DOI: 10.1039/c9ra01643k

rsc.li/rsc-advances

\section{Formation and characterization of polytetrafluoroethylene nanofiber membranes for high-efficiency fine particulate filtration}

\author{
Huan Xu, ${ }^{a}$ Wangyong Jin, ${ }^{\mathrm{b}}$ Feng Wang, ${ }^{\text {ac }}$ Guojin Liu, ${ }^{a}$ Chengcai Li, ${ }^{a}$ Jieqi Wang, ${ }^{a}$ \\ Hailin Zhu (D) *ac and Yuhai Guo (DD *a
}

Polytetrafluoroethylene (PTFE) porous membranes are widely used for high-temperature filtration. The polytetrafluoroethylene nanofiber membranes for fine particulate filtration were prepared by sintering the precursor electrospun polytetrafluoroethylene/polyvinyl/boric acid alcohol composite membranes. The effects of PTFE/PVA mass ratio and sintering temperature on the morphology and properties of the prepared membranes were investigated to obtain the PTFE nanofibers with different diameters, and the film has been characterized by SEM, TG, XRD, FT-IR, and EDS, and the mechanical and hydrophobic properties of the membranes were also investigated. The PTFE nanofiber membranes after sintering had nanofiber and nanowire structures. Moreover, the membranes were tested in air filtration. The filtration efficiency and pressure drop were tested to evaluate the membrane permeability and separation properties. The results showed a high filtration efficiency (98\%) and a low pressure drop (90 $\mathrm{Pa}$ ) for

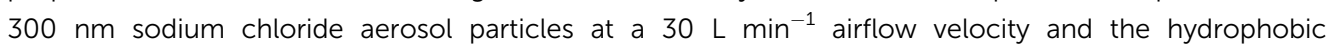
membranes showed durable self-cleaning properties, which suggested that the PTFE nanofiber membranes were a promising candidate for high temperature filtration applications.

\section{Introduction}

Air pollution, as a primary environmental problem, has attracted increasing attention due to rapid urbanization and industrialization. ${ }^{\mathbf{1}}$ More than two million premature deaths each year can be attributed to the effects of urban outdoor air pollution and indoor air pollution, particularly in developing countries. ${ }^{2}$ Fine particles with an aerodynamic diameter less than $2.5 \mu \mathrm{m}$, were considered to be a major cause of adverse health effects ranging from the human respiratory tract to extrapulmonary organs..$^{3-5}$ Moreover, stricter emission limits for fine particle emissions from industrial processes and automotive exhaust have also contributed to the urgent need for high performance filters with high filtration efficiency, low energy cost, and long service life. ${ }^{6,7}$ The conventional filtration media, including meltblown fibers, glass filters, and spun-bonded fibers, are known to exhibit relatively low filtration efficiency and high energy consumption, as well as being unsuitable for the filtration of fine particles due to the micro-sized fiber diameter and depth loading characteristics. ${ }^{\mathbf{8 9}}$ Template synthesis, phase separation, melt-blown methods, and plasma treatment have been

${ }^{a}$ Zhejiang Provincial Key Laboratory of Fiber Materials and Manufacturing Technology, Zhejiang Sci-Tech University, Hangzhou, 310018, China. E-mail: zhhailin@163.com; gyh@zstu.edu.cn

${ }^{b}$ Zhejiang Dong Da Environment Engineering Co., Ltd, Zhuji 311800, China

${ }^{c}$ Zhejiang Kertice Hi-Tech Fluor-Material Co., Ltd, Huzhou 313000, China developed to fabricate nanofiber-based membranes for separation of fine particles. ${ }^{\mathbf{1 0 - 1 4}}$ But most of the filters still suffer from low filtration efficiency and high energy consumption, as well as being unsuitable for the filtration of fine particles. In the past decade, electrospun nanofibers have widely been used as fibrous filters for air filtration. ${ }^{15-23}$ Electrospinning has emerged as a promising technology in air filtration and water purification devices because of the advantageous features of controllable fiber diameter, high porosity, remarkable specific surface area, low packing density. Nevertheless, those membranes may not be able to withstand high temperature for a long time.

Polytetrafluoroethylene (PTFE) is well known for its outstanding thermal stability, chemical resistance, low surface energy and good electrical insulation. ${ }^{24-28}$ Porous PTFE membranes ${ }^{28-31}$ and PTFE bag filters ${ }^{32-34}$ have been widely used as high-temperature filters. Most of the filters for hot gas filtration are made of nonwoven fabrics of PTFE, ${ }^{35} \mathrm{PPS},{ }^{36}$ glass, ${ }^{37}$ ceramic $^{38}$ and metal fiber. ${ }^{39}$ For PTFE nanofiber membrane, it has potential as hot gas filter media and so far litter has been reported about the application of PTFE nanofiber membranes for hot gas filtration.

Due to the superior solvent resistance and the high melt viscosity, $^{\mathbf{4 0 , 4 1}}$ PTFE fiber is prepared by the methods of membrane-splitting and paste-extrusion. In the preparation process, a lot of lubricants are used which may be harmful to the environment. In this paper, PTFE nanofiber membranes were prepared by sintering PTFE/PVA/BA electrospun 
membranes (emulsion electrospinning). Emulsion electrospinning is considered as green and environmental method to fabricate fibrous membranes from water based emulsions together with small amount of water soluble polymer as a matrix. This method not only could avoid using a large amount of toxic organic solvents but also could be used to process unspinnable polymer particles into fibers. ${ }^{42-45}$ We used the complexing property of BA and PVA and prepared spinning solution by adding a little amount of BA solution into the mixed liquids with different mass concentrations of PVA and PTFE emulsion. PVA (10 wt $\%$ ) was chosen as assistant spinning due to its water solubility, low cost, easy spinning property and low decomposition temperature. The effect of PTFE/PVA ratio and sintering temperature on the morphology and properties of PTFE nanofiber membranes for air filtration are investigated. PTFE nanofibrous membranes are designed for water resistant and breathability application because of the high hydrophobicity, high fracture toughness and low surface friction. Further studies show that the PTFE nanofiber membranes have high porosity and complex pore geometries that give the membranes high filtration efficiency with low pressure drop.

Thus far, Xiong et al. $^{\mathbf{4 6}}$ reported an inspiring work in which fibrous PTFE membranes were fabricated through electrospinning and sintering and PTFE nanofiber membranes have been widely exploring and adopted for versatile application, such as dye degradation, ${ }^{47}$ photocatalytic degradation, ${ }^{48,49}$ waterproof-breathable application, ${ }^{50}$ vacuum membrane distillation, ${ }^{31,51}$ the separator for lithium-ion batteries, ${ }^{52}$ the highperformance triboelectric nanogenerators, ${ }^{53}$ the oil/water separation. ${ }^{\mathbf{5 4 5 5}}$ However, research in air filtration has hardly been carried out.

\section{Experimental}

\subsection{Materials}

All materials were purchased commercially and were used without further purification. PTFE emulsion (TE3859) in water (60\%) was obtained from Dongguan Dongzhan plastic trade Co., Ltd. The PTFE particles in the emulsion have an average size of $80 \mathrm{~nm}$. PVA1799 was provided by Sichuan Vinylon Factory (China) and boric acid (BA) was purchased from Zhejiang Transfar Technology Co., Ltd (China). The water used in this work was distilled water.

\subsection{PTFE nanofiber membranes preparation}

2.2.1 Emulsion electrospinning. BA powder was dissolved in distilled water in a vial by stirring for $2 \mathrm{~h}$ at room temperature to prepare BA solution (4 wt\%). PVA solution (10 wt $\%$ ) was prepared by dissolving PVA powder in distilled water at $90{ }^{\circ} \mathrm{C}$ under constant stirring for $3 \mathrm{~h}$. The PTFE emulsion and amount of BA solution (100 $\mu \mathrm{L} / 10 \mathrm{~g}$ PVA) were added to PVA solution with different mass ratios and followed by continuous stirring for at least $10 \mathrm{~h}$ to form spinning solution which concentration was $26 \%$ at room temperature. The mass ratios of PTFE/PVA were $3: 1,4: 1,5: 1,6: 1$ and $7: 1$, respectively. BA was added to mixed solution and reacted complexing with PVA which could increase the spinning solution viscosity to avoid PTFE agglomeration. A direct current voltage of $15 \mathrm{kV}$ was applied at a distance of $15 \mathrm{~cm}$ between the needle and collector screen which was made by an aluminum foil. The nanofiber membranes were collected by a steel mesh for $8 \mathrm{~h}$ and the flow rate was $0.5 \mathrm{~mL} \mathrm{~h}^{-1}$, as depicted in Fig. 1 .

2.2.2 PTFE membranes preparation. The electrospun PTFE/PVA/BA as-spun composite fiber membranes were dried for $6 \mathrm{~h}$ at $70^{\circ} \mathrm{C}$ and then were sintering at 340, 360, 380, 390 and $410{ }^{\circ} \mathrm{C}$ (Sgl-1200 Tupe Lab Furnace, Shanghai Daheng Optics and Fine Mechanics Co., Ltd) for $20 \mathrm{~min}$ at a heating rate of $10{ }^{\circ} \mathrm{C} \mathrm{min}^{-1}$ to remove PVA and get the pure PTFE fibrous membranes. During the sintering process nitrogen atmosphere was maintained until the temperature was back to room temperature. Fig. 2 showed the schematic preparation of PTFE nanofiber membranes by emulsion electrospinning and sintering and schematic the filtration process of the PTFE nanofiber membranes for particles.

\subsection{Characterization and measurements}

2.3.1 Morphology of PTFE nanofiber membranes. The morphologies of PTFE nanofiber membranes were investigated

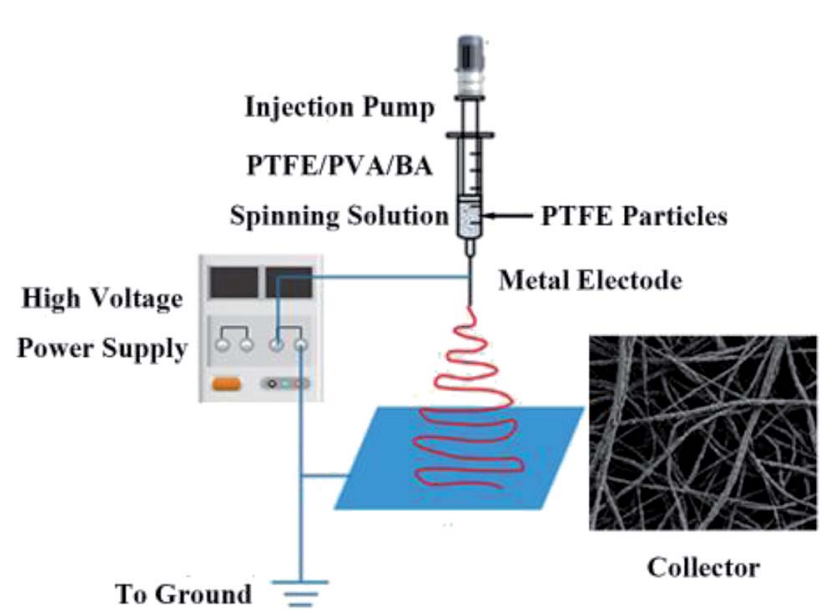

Fig. 1 Schematic diagram illustrating the fabrication of PTFE/PVA fibrous membranes and typical FE-SEM image of PTFE/PVA membrane.

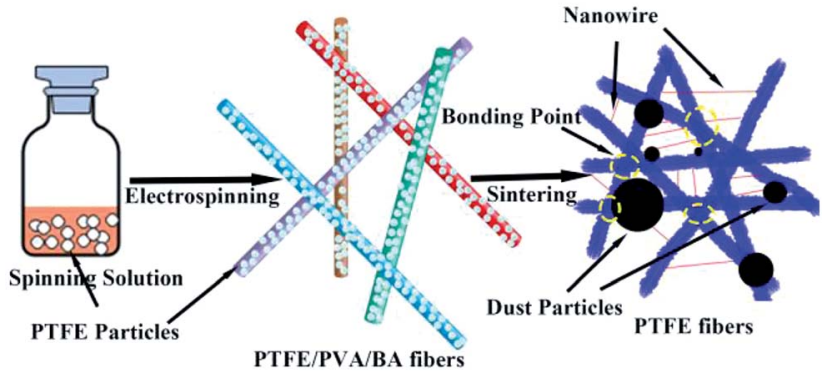

Fig. 2 Schematic preparation of pure PTFE electrospun nanofibers by emulsion electrospinning and sintering, and filtration process of the PTFE nanofiber membranes for aerosol particles. 
with a FESEM equipped with an X-ray energy dispersive spectrometer (EDS) (EVO MA 25, ZEISS, Germany). The PTFE nanofiber membranes were frozen in liquid nitrogen, fractured to obtain fragments, and sputtered with platinum using a HITACHI E-1010 Ion Sputtering device for FESEM observation. EDS detector was used to determine the existence of PVA.

2.3.2 Porosity and pore size distribution. The over porosity was usually determined by the gravimetric method, determining the weight of liquid contained in the membrane pores. The porosity $\varepsilon$ of the PTFE nanofiber membrane was calculated by the following equation:

$$
\varepsilon=\frac{w_{1}-w_{2} / \rho_{1}}{w_{1}-w_{2} / \rho_{1}+w_{2} / \rho}
$$

Here, $w_{1}$ is the weight of the wet PTFE nanofiber membrane, $w_{2}$ is the weight of the dry PTFE nanofiber membrane, $\rho_{1}$ is the liquid density, which equals $0.816 \mathrm{~g} \mathrm{~mL}^{-1}$, and $\rho$ is the polymer density, which the density of PTFE is $2.2 \mathrm{~g} \mathrm{~mL}^{-1}$. The pore size distribution of the PTFE nanofiber membranes was investigated by using a Capillary Flow Porometer (Porometer 3GZH Quantachrome Instruments, USA). The nanofiber membranes were fully wetted with the Gq16, and then the measurements were carried out following the procedure described in the literature. ${ }^{56}$ The pore size distribution was determined with the aid of the computer software coupled to the capillary flow porometer.

2.3.3 Contact angle. The contact angles of the membranes were measured by a contact angle measuring system (SL200KB, America).

2.3.4 Mechanical strength and thickness. The tensile mechanical property was measured on a tensile tester (KEG-G1, Kato-Tech Co., Ltd. Japan). Strip samples with a width of $5 \mathrm{~mm}$ and a length of $40 \mathrm{~mm}$ were tested with a crosshead speed of 10 $\mathrm{mm} \min ^{-1}$. The thickness of the samples was measured by a screw micrometer. All the samples were tested for 5 times to give the average values.

2.3.5 IR and XRD examination. The Fourier transform infrared (FTIR) spectra was recorded on a Nicolet 5700 spectrometer (Thermo Fisher Scientific, USA) to determine the residual extent of PVA in each sample before or after sintering treated. X-ray diffraction (XRD, Bruker D8, Germany) was used to elucidate the crystal structure of samples.

2.3.6 DSC and TGA examination. The differential scanning calorimeter (DSC, NETZSCH DSC 200PC) analysis of the PTFE nanofiber membrane was performed to determine the melting temperature. For the purpose of getting the initial softening temperature, samples were heated up from 30 to $380{ }^{\circ} \mathrm{C}$ at a heating rate of $10{ }^{\circ} \mathrm{C} \mathrm{min}^{-1}$. Thermal stabilities were examined by thermogravimetric analyser (TGA, Seiko-6300, Japan) in nitrogen atmosphere with a heating rate of $10{ }^{\circ} \mathrm{C} \mathrm{min}^{-1}$.

\subsection{Applications of air filtration}

A TSI Model 8130 Automated Filter Tester (TSI, Inc., MN, USA) was used to measure the filtration efficiency and filter resistance (Fig. 3). The device is attached to a particle generator which generates charge neutralized micron monodisperse solid $\mathrm{NaCl}$ particles of $0.3 \mu \mathrm{m}$ in diameter. The neutralized $\mathrm{NaCl}$ aerosols

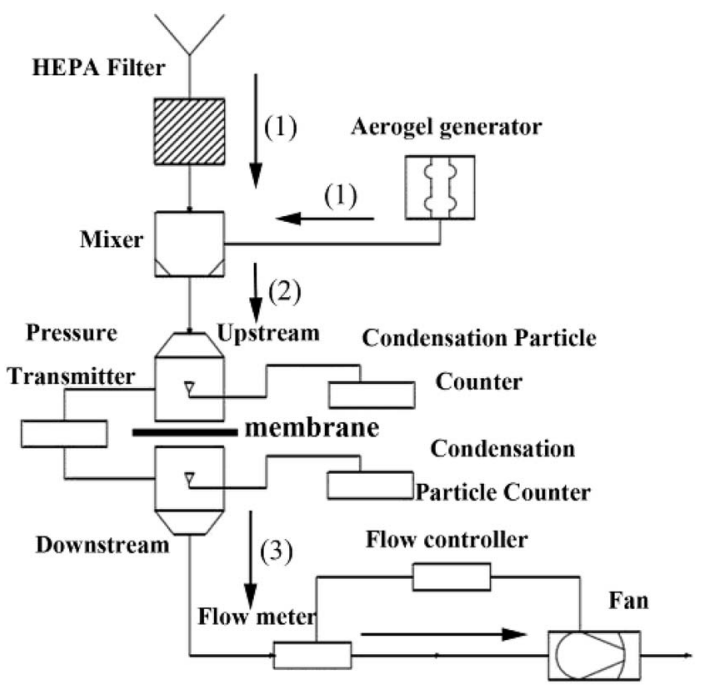

Fig. 3 Schematic diagram of the experimental setup for a particulate generation, filtration, and measurement system.

were fed into a filter holder and down through the filter with 100 $\mathrm{cm}^{2}$ of effective area. Two, solid-state, laser photometers enable these filter testers to measure aerosol concentration levels both upstream and downstream of the filter under testing. The filter resistance was measured with a combination of a flow meter and two electronic pressure transducers that detected the pressure drop through the filter media under testing. All $\mathrm{NaCl}$ aerosol tests were conducted at room temperature. The air before and after the membrane filters was sampled, and the filtration efficiency of the membrane filter was determined using

$$
\eta=\left(C_{0}-C\right) / C_{0}
$$

where $C_{0}$ and $C$ correspond to the particle number concentration before and after the membrane filters.

The quality factor (QF), which is usually taken as the criterion for comparing filtration performance of different filters, is expressed as: ${ }^{57}$

$$
\mathrm{QF}=\frac{\ln (1-\eta)}{\Delta P}
$$

where $\eta$ and $\Delta P$ is the filtration efficiency and pressure drop, respectively. The higher collection efficiency with lower possible pressure drop result in a better filter media.

\section{Result and discussion}

\subsection{Effects of solution parameters on fiber morphology}

The SEM images of the membranes prepared by electrospinning under certain condition and the mass ratios of PTFE/PVA were $3: 1,4: 1,5: 1,6: 1$ and $7: 1$, respectively were shown in Fig. 4. In order to improve the mechanical and filtration performance of PTFE nanofiber membrane, the fibers should be uniform without a lot of beads. When the mass ratios of PTFE/PVA were $6: 1$ and $7: 1$, many beads and needle-like short fibers 


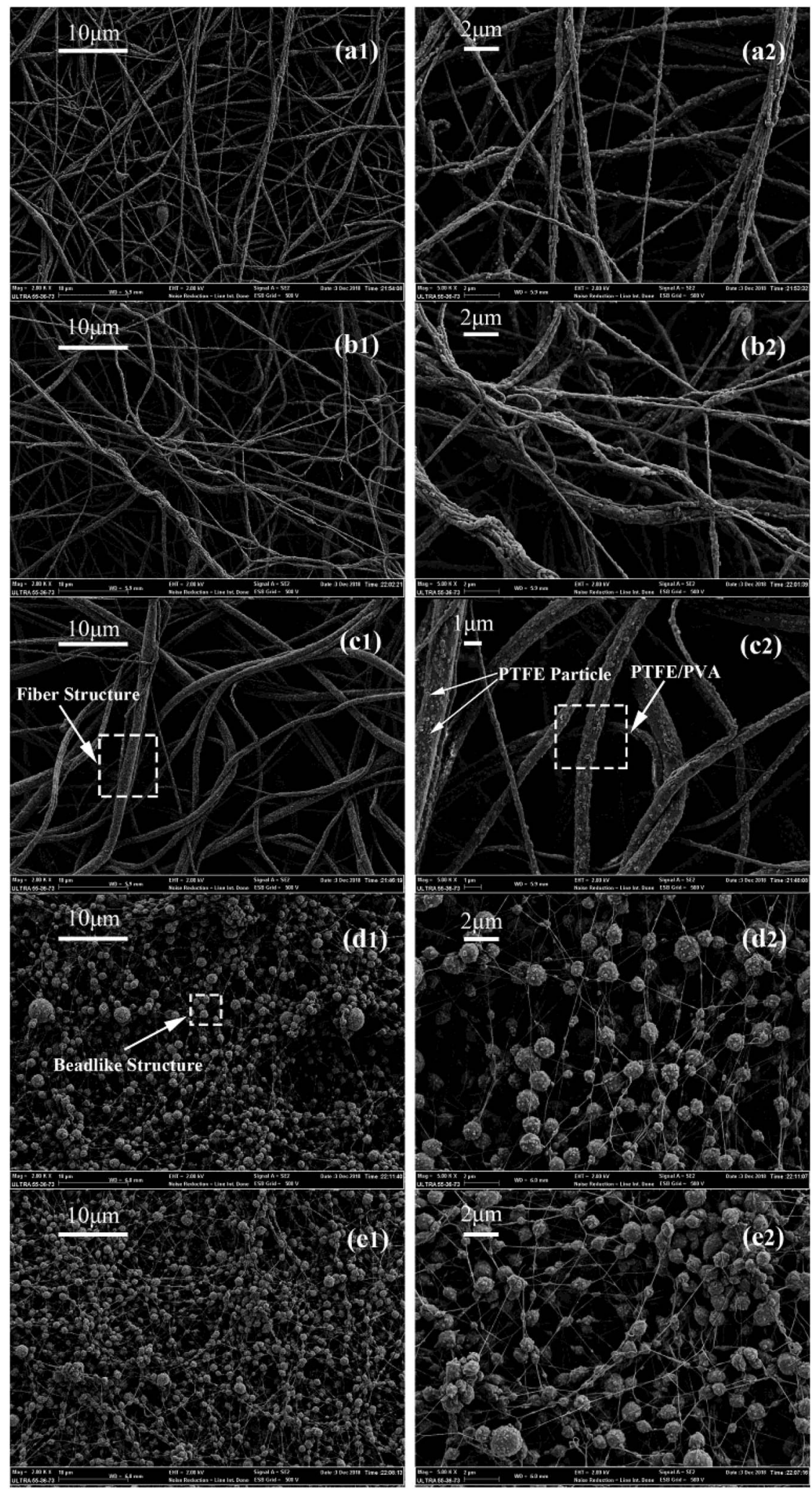

Fig. 4 Morphologies of precursor electrospun PTFE/PVA composite membranes at different PTFE/PVA mass ratios ((a1 and a2), 3 : 1; (b1 and b2), $4: 1 ;(c 1$ and c2), $5: 1 ;(d 1$ and d2), $6: 1$; (e1 and e2), $7: 1 ; a 1-e 1, \times 2000$ surface; a2-e2, ×5000 surface).

appeared. This morphology (Fig. 4(d) and (e)) could be because the amount of PVA was too small to efficiently binder the PTFE nanoparticles each other into a continuous fiber form. The beads decreased and the fibers became continuous by increasing the PVA amount (Fig. 4(a)-(c)). The precursor nanofiber membrane was composed of a random array of nanofibers. 
A small part of the PTFE particles were attached to the fiber surface, which most of them were wrapped inside the fiber. As shown in Fig. 5, when the mass ratios of PTFE/PVA decreased from $5: 1$ to $3: 1$, the structure of the film morphology change constantly, and fiber diameter decreased from $591.63 \mathrm{~nm}$ to $219.10 \mathrm{~nm}$ because of the decrease of PTFE nanoparticles.

From the Fig. 6, changes could be seen between the as-spun composite fiber membrane and the membrane after sintering. The membrane after sintering was still composed of nanofibers, and the fibers tended to melt and produced a crosslinked fiber network. As the amount of PVA reducing gradually, the fibers of calcinated membranes were more and more clearly. Meanwhile, the fibers became thicker after heat treatment because of the melting of PTFE. As the mass ratio of PTFE/PVA increased, the membranes became PTFE resins rather than fibers. As shown in Fig. 7, when the mass ratio of PTFE/PVA varied from $5: 1$ to $3: 1$, the structure of the membrane morphology changed constantly, and sintered fiber diameter decreased from $1420.15 \mathrm{~nm}$ to $796.90 \mathrm{~nm}$. Less PVA should be introduced in spinning solution in order to obtain uniform PTFE fiber membranes and the thinner fibers were good for air filtration. Therefore, the electrospun PTFE/PVA composite fibers and their membranes from the blend with the PTFE : PVA weight ratio of $4: 1$ were used for the following investigations.

\subsection{The thermal properties of the as-spun composite nanofiber membrane}

The thermal properties were evaluated by TGA and DSC analysis. As shown in Fig. 8(a), the connection between the weight change of the precursor membrane (PTFE : PVA $=7: 3$ ) was verified by the TG curve. There were three weight-loss in the TG curves. The first weight loss was around $250{ }^{\circ} \mathrm{C}$ because of the vaporization of surfactant. The second weight loss occurred between $300-350{ }^{\circ} \mathrm{C}$, which was corresponding to the decomposition of PVA. The last weight loss started at $500{ }^{\circ} \mathrm{C}$, which was attributed to the decomposition of PTFE. The result showed that the PTFE was preserved well. The PVA completely decomposed between 330 and $430{ }^{\circ} \mathrm{C}$ and the pure PTFE was thermal stable until $500^{\circ} \mathrm{C}$. DSC curve of PTFE nanofiber membrane was shown in Fig. 8(b), it is observed that the nanofiber membrane does not appear to melt until the temperature reached $327^{\circ} \mathrm{C}$. It could be seen that the PTFE nanofiber membrane had excellent thermal stability performance, which had a promising candidate for high temperature filtration applications.

\subsection{Effect of sintering temperature on the fiber morphology}

The SEM images of the PTFE nanofiber membranes after sintering at different temperature were shown in Fig. 9.

In the sintering process, the PVA component decomposed and the PTFE particles gradually fused. As shown in Fig. 9(a), before sintering, the as-spun composite nanofiber membrane was composed of a random array of nanofibers. A few of PTFE particles were inlaid on the fiber surface and most of them were wrapped inside the fibers. The membrane was still composed of fibers and there are no obvious changes in fiber morphology when the sintering temperature below $380{ }^{\circ} \mathrm{C}$, though sintered above the melting point of PTFE. When the temperatures were $340{ }^{\circ} \mathrm{C}$ (Fig. 9(b)) and $360{ }^{\circ} \mathrm{C}$ (Fig. 9(c)), though the PTFE
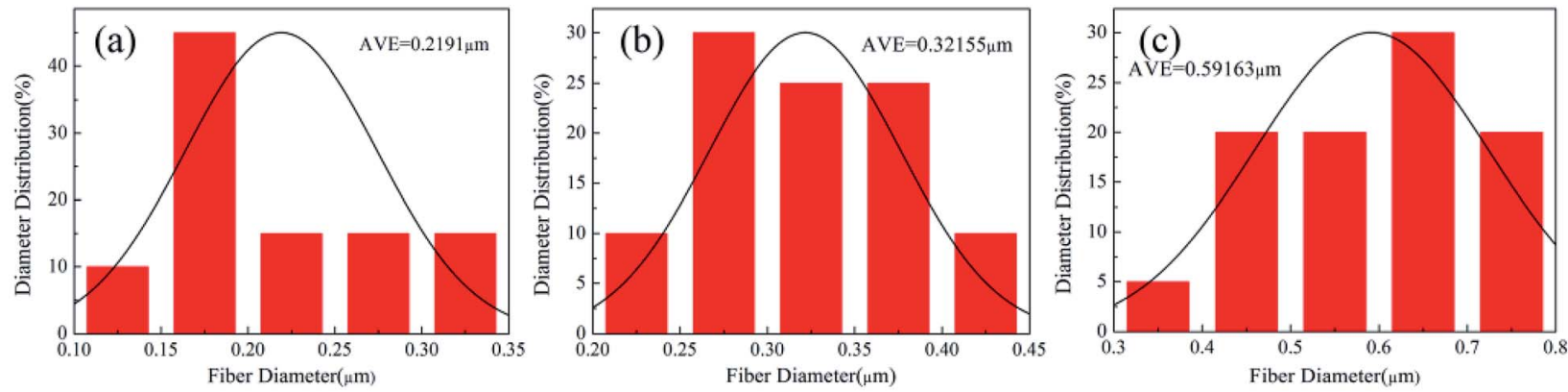

Fig. 5 The diameter distribution of electrospun PTFE/PVA composite membranes at different mass ratios (a) $3: 1$; (b) $4: 1$; (c) $5: 1$.
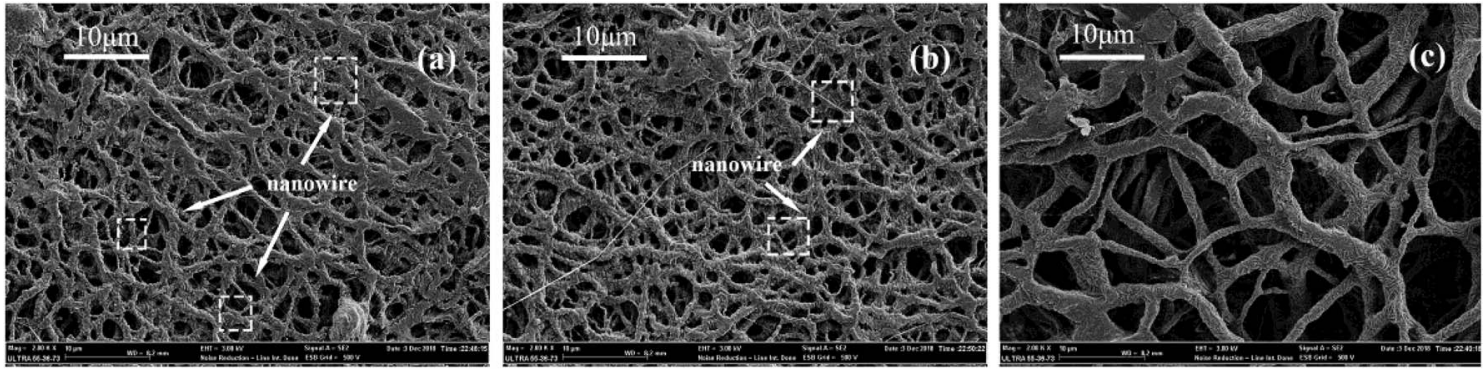

Fig. 6 Morphologies of precursor electrospun PTFE/PVA composite membranes at different PTFE/PVA mass ratios sintered at $380{ }^{\circ} \mathrm{C}$, (a) 3 : 1 ; (b) $4: 1$; (c) $5: 1$. 

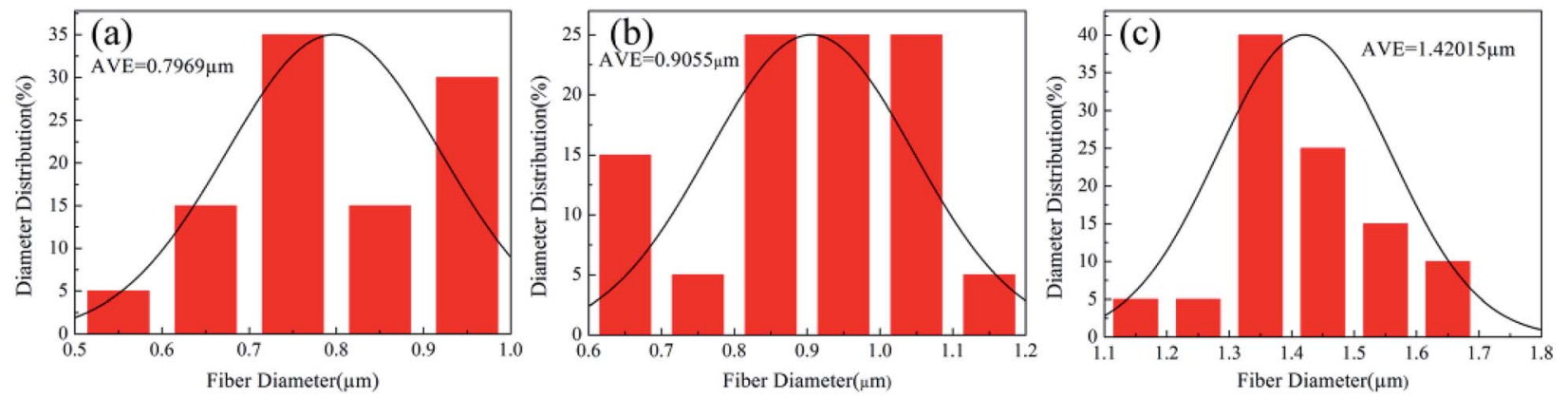

Fig. 7 The diameter distribution of electrospun PTFE/PVA composite membranes at different mass ratios sintered at $380{ }^{\circ} \mathrm{C}$ (a) $3: 1 ;$ (b) $4: 1 ;$ (c) $5: 1$.
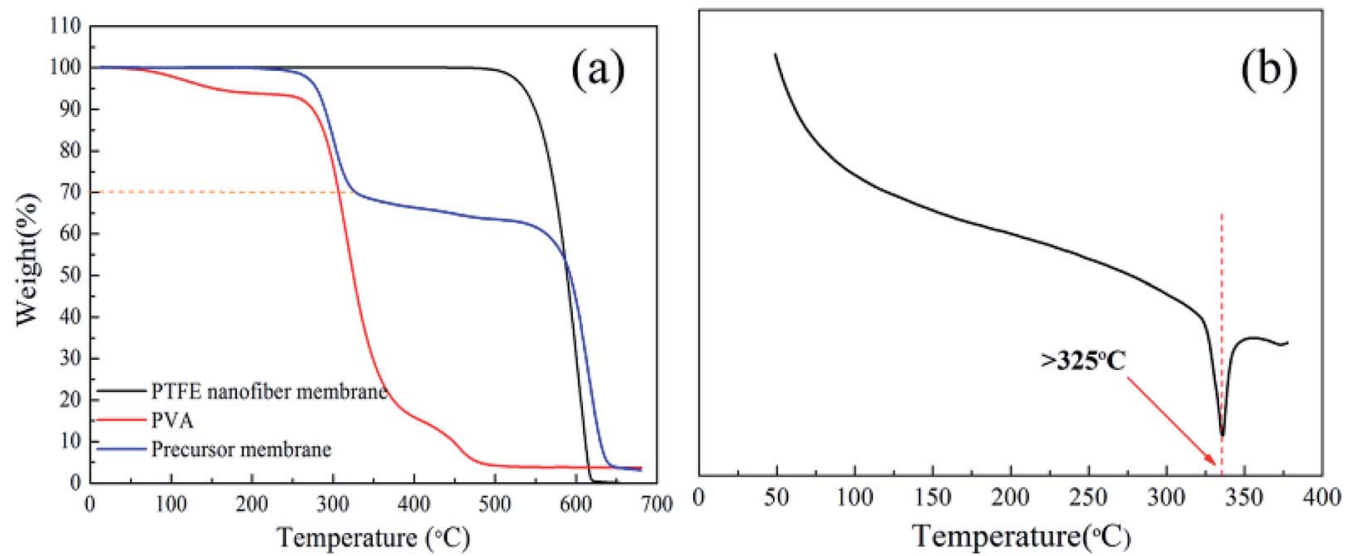

Fig. 8 (a) TG curve of the as-spun composite membrane, PVA and PTFE nanofiber membrane; (b) DSC curve of PTFE nanofiber membrane.

particles began to melt and the fibers showed consecutively, some PTFE particles still appeared on the surface of the fibers. The morphology of the membrane treated at 380 and $390{ }^{\circ} \mathrm{C}$ were shown in Fig. 9(d) and (e). The membranes were still composed of a random array of nanofibers, but on the fiber crosslinking points, the fibers tended to melt in the fibers intersections resulting in bonding and formed a connected fiber mesh structure. On the fiber surface, grooves arranged transversely due to the PTFE melted and fluxed to fill the cavities caused by the PVA decomposition to keep the fiber shape. The unique structures provided the multiple scale roughness, which was not only important for forming hydrophobic surface, but also important for improving the effective area for air filtration. As shown in Fig. 9(f), further increasing the temperature to $410{ }^{\circ} \mathrm{C}$ led to the shrinkage of fibers and junctionformation between fibers. This mechanical performance of the PTFE membrane sintering at $410{ }^{\circ} \mathrm{C}$ might be due to the high temperature $\left(410^{\circ} \mathrm{C}\right)$ leading to partial degradation of PTFE macromolecular chain.

\subsection{The effect of sintering temperature on the composition of the fibers}

Further investigation by EDS was performed to prove the effect of sintering temperature on the composition of the fibers. It was shown in Fig. 10, the EDS patterns revealed that the as-spun nanofiber membranes surface contained $\mathrm{C}$, $\mathrm{O}$, and $\mathrm{F}$, which three characterized peaks were at $0.27,0.52$ and $0.68 \mathrm{keV}$. When the sintering temperatures were $340{ }^{\circ} \mathrm{C}$ and $360{ }^{\circ} \mathrm{C}$, the three characterized peaks still appeared. It showed that there was still a small amount of PVA in PTFE nanofiber membranes. After the sintering temperature above $380{ }^{\circ} \mathrm{C}$, the signal form oxygen element was disappeared. The pure PTFE nanofiber membranes could be got when the sintering temperature was above $380{ }^{\circ} \mathrm{C}$.

The chemical structure and composition of before and after sintering $\left(380^{\circ} \mathrm{C}\right)$ were confirmed by FT-IR as shown in Fig. 11 . The bands around 1210 and $1155 \mathrm{~cm}^{-1}$ were assigned for $\mathrm{C}-\mathrm{F}$ stretching vibrations, and the brands near 2937 and $3315 \mathrm{~cm}^{-1}$ are characteristic for PVA. When the stretching temperature increased at $380{ }^{\circ} \mathrm{C}$, the characteristic bands for PVA disappeared because of the decomposition of PVA. The result showed that the PVA was completely removed, and PTFE nanofiber membranes were successfully prepared.

\subsection{The effect of sintering temperature on the crystallinity of the PTFE nanofiber membranes}

The X-ray diffraction pattern of pure PTFE nanofiber membranes was shown in Fig. 12. There were peaks observed at $2 \theta=18.15^{\circ}, 31.8^{\circ}, 37.15^{\circ}$ and $41.5^{\circ}$, which could be indexed to (100), (110), (107) and (108) of PTFE, respectively. The peak at $2 \theta$ $=18.15^{\circ}$ was considered as the crystallinity phase of PTFE while 

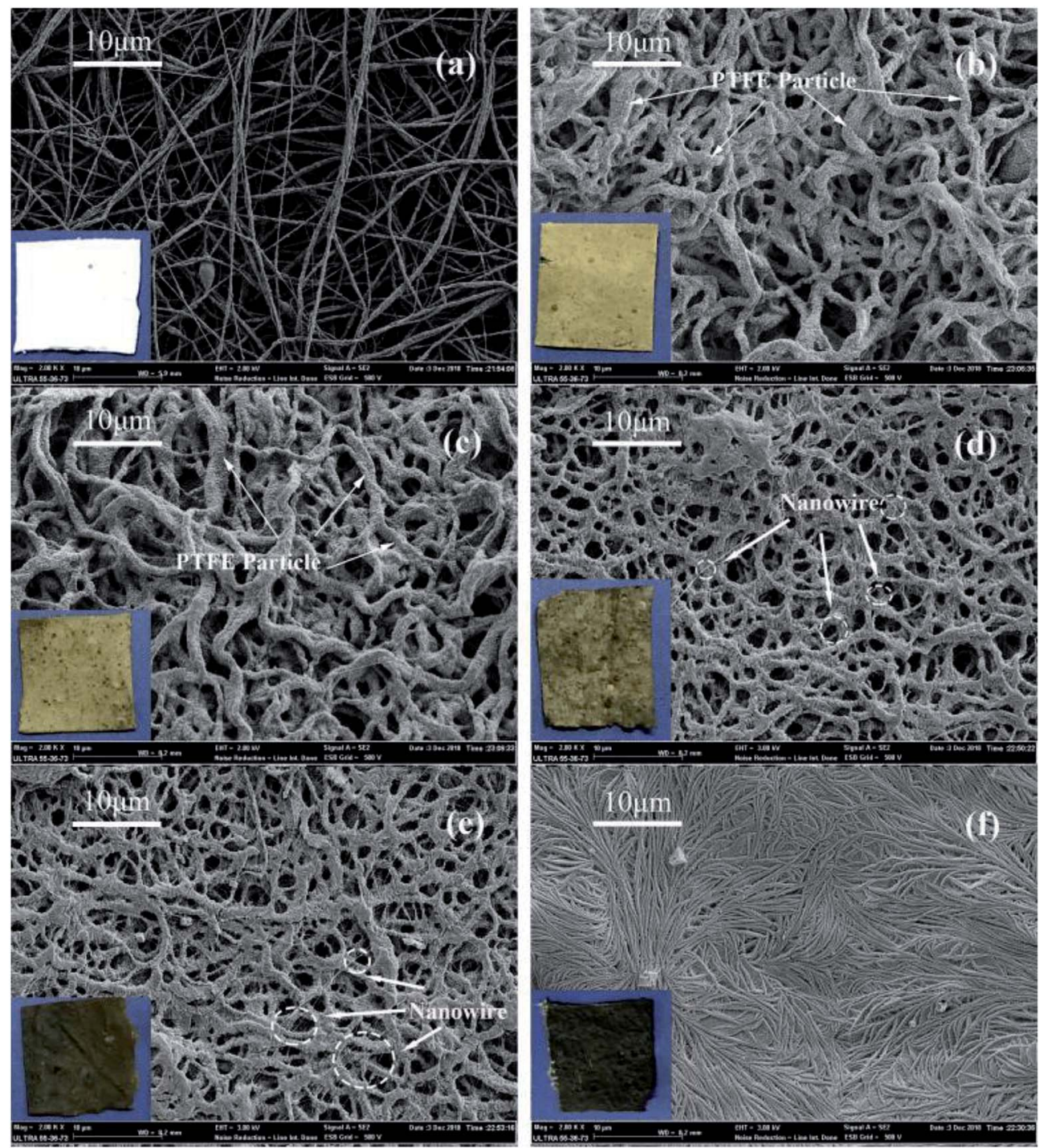

Fig. 9 Morphologies of precursor electrospun PTFE/PVA composite membranes sintered at different temperatures (PTFE/PVA mass ratio was 4 : 1) (a) $0{ }^{\circ} \mathrm{C}$; (b) $340{ }^{\circ} \mathrm{C}$; (c) $360{ }^{\circ} \mathrm{C}$; (d) $380{ }^{\circ} \mathrm{C}$; (e) $390{ }^{\circ} \mathrm{C}$; (f) $410{ }^{\circ} \mathrm{C}$.

other two peaks were considered as the amorphous phase. The degree of crystallinity could be calculated by dividing the integrated area of the reflection peak at $2 \theta=18.15^{\circ}$ from the sum of the integrated areas of the whole three characterized peaks. The as-spun PTFE nanofiber membrane had the highest degree of crystallinity compared with the membranes after sintering. It was because the PTFE particles experienced first melting and then cooling down to room temperature to decrease the crystallinity of the PTFE nanofiber membranes. The peak at $2 \theta=$ $18.15^{\circ}$ dropped down at first and then increased with the raised of sintered temperature. When the temperature reached $410^{\circ} \mathrm{C}$, the diffraction peak intensity did not appear to add up which was due to that there was no improvement of the crystallinity.

\subsection{The effect of sintering temperature on the mechanical properties}

The relationship between tensile strength and elongation at break at different sintering temperatures were illustrated in
Fig. 13. A comparatively high degree of crystallinity was benefit to get the high mechanical performance. Although the as-spun nanofiber membrane had a higher degree of crystallinity than the membranes after sintering, the as-spun nanofiber membrane showed poor mechanical performance. The as-spun nanofiber membrane was flexible with a high elongation value. It was because that the as-spun membranes were consisted of random nanofibers without crosslinking. When the load was applied, nanofibers could adjust their orientation enough. When the temperature was below $390{ }^{\circ} \mathrm{C}$, with the sintering temperature increased the tensile strength enhanced. When the membrane was sintering at $340^{\circ} \mathrm{C}$, the PTFE membrane showed the smallest tensile strength of $2.5 \mathrm{MPa}$ and elongation at break of $35 \%$, which due to the incomplete melting of PTFE particles at the lower sintering temperature. After that, when the sintering temperatures were $380^{\circ} \mathrm{C}$ and $390{ }^{\circ} \mathrm{C}$, the tensile strength improved obviously. Defects might partly be filled by PTFE melt and the PTFE in nanofibers began to fuse and appeared the 

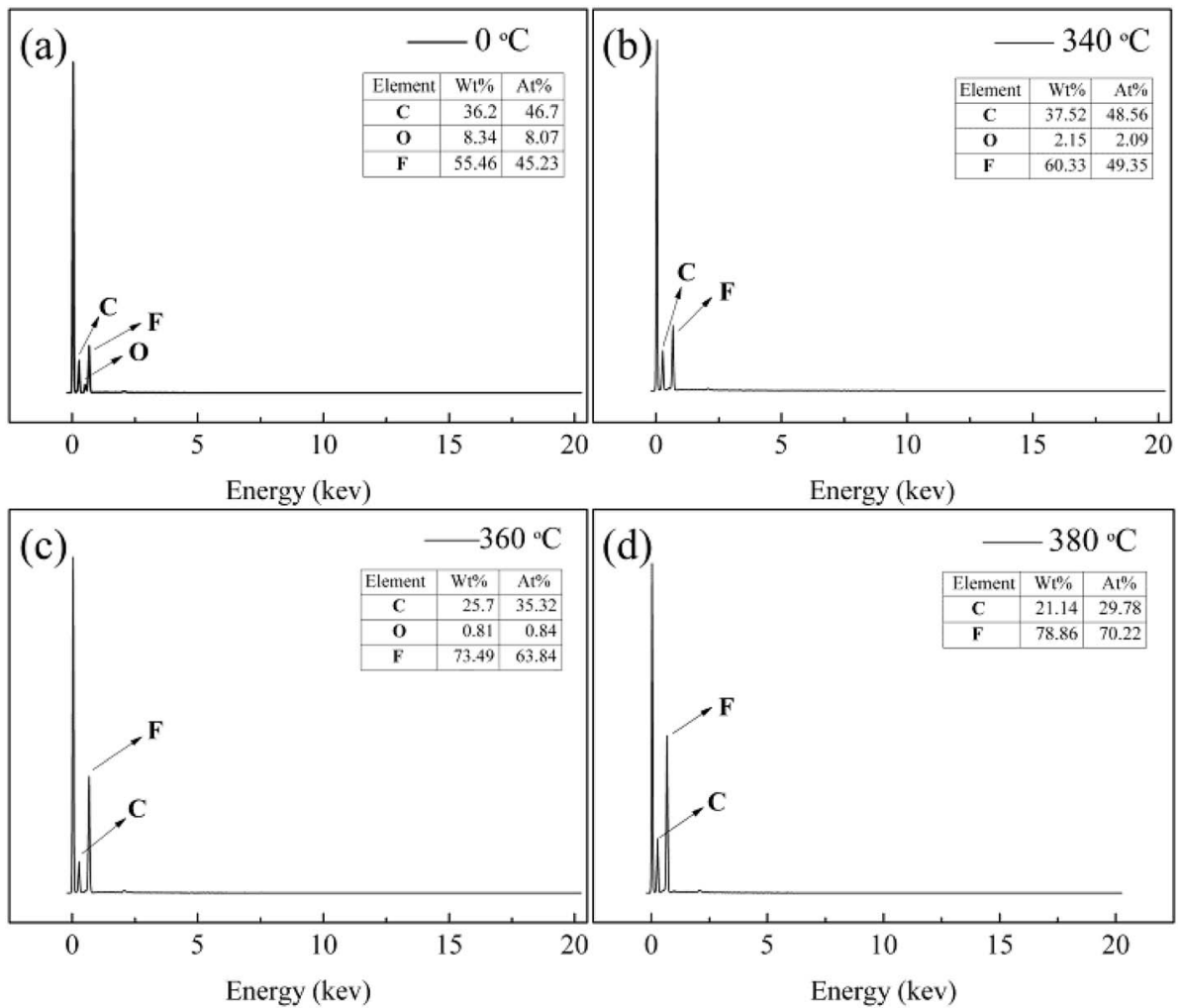

Fig. 10 EDS curves of PTFE/PVA precursor membranes before (a) and sintered different temperatures (b) $340{ }^{\circ} \mathrm{C}$; (c) $360{ }^{\circ} \mathrm{C}$; (d) $380{ }^{\circ} \mathrm{C}$ (PTFE/ PVA mass ratio was $4: 1$ ).

crosslinking point to form an interconnected fibrous network structure. The membranes could be stronger with the help of the bonding between the fibers. The tensile strength of the membranes treated at $410{ }^{\circ} \mathrm{C}$ was weaker than that of the membranes treated at $380{ }^{\circ} \mathrm{C}$ and $390{ }^{\circ} \mathrm{C}$. The mechanical properties of nanofiber membranes decreased when curing at higher temperatures although the temperatures were lower than the decomposition temperature of PTFE. This mechanical performance of the PTFE membrane sintering at $410{ }^{\circ} \mathrm{C}$ might be due to the high temperature $\left(410{ }^{\circ} \mathrm{C}\right)$ leading to partial degradation of PTFE macromolecular chain.

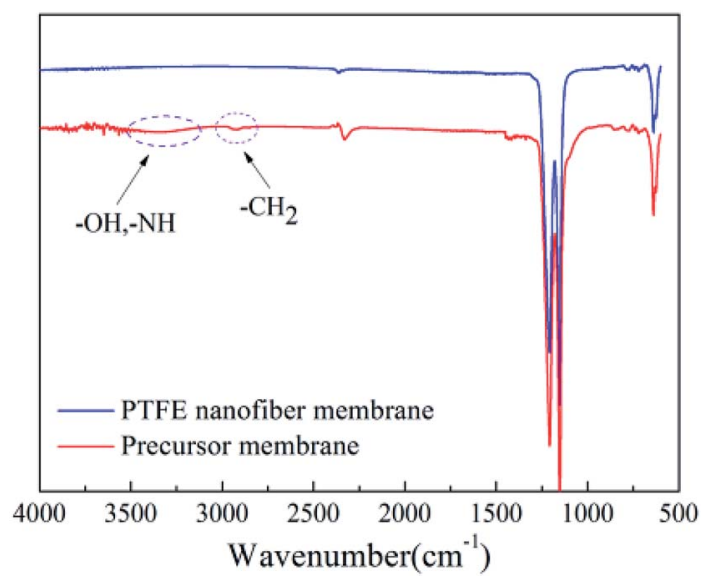

Fig. 11 IR spectrums of PTFE nanofiber membrane and precursor membrane.

\subsection{The hydrophobicity of the pure nanofiber membrane}

Hydrophobicity was an important property for air filtration, which could make membranes have the property of durable self-cleaning. The water contact angle of sintered membranes treated at different temperatures and different mass ratios was shown in Fig. 14, Tables 1 and 2. The water contact angle of the as-spun nanofiber membrane was calculated to be about $28^{\circ}$ (Fig. 14(c)). It was due to that the as-spun nanofiber membranes had a PVA concentration of about $20 \%$ and the huge specific surface area because of the ultrafine fibrous structure. When

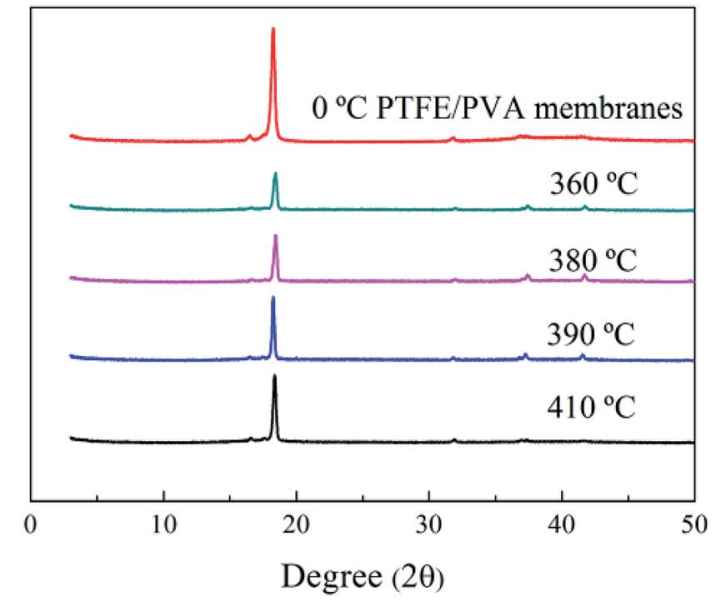

Fig. 12 XRD patterns of PTFE/PVA precursor membranes sintered different temperatures. 
the mass ratios of the PTFE/PVA membranes increased from $3: 1$ to $5: 1$, more and more PTFE particles were attached to the fiber surface, which increased the roughness of the membranes and improved the water contact angle. After sintering at different temperatures, the membranes became hydrophobic and the water contact angle varies with increasing the sintering
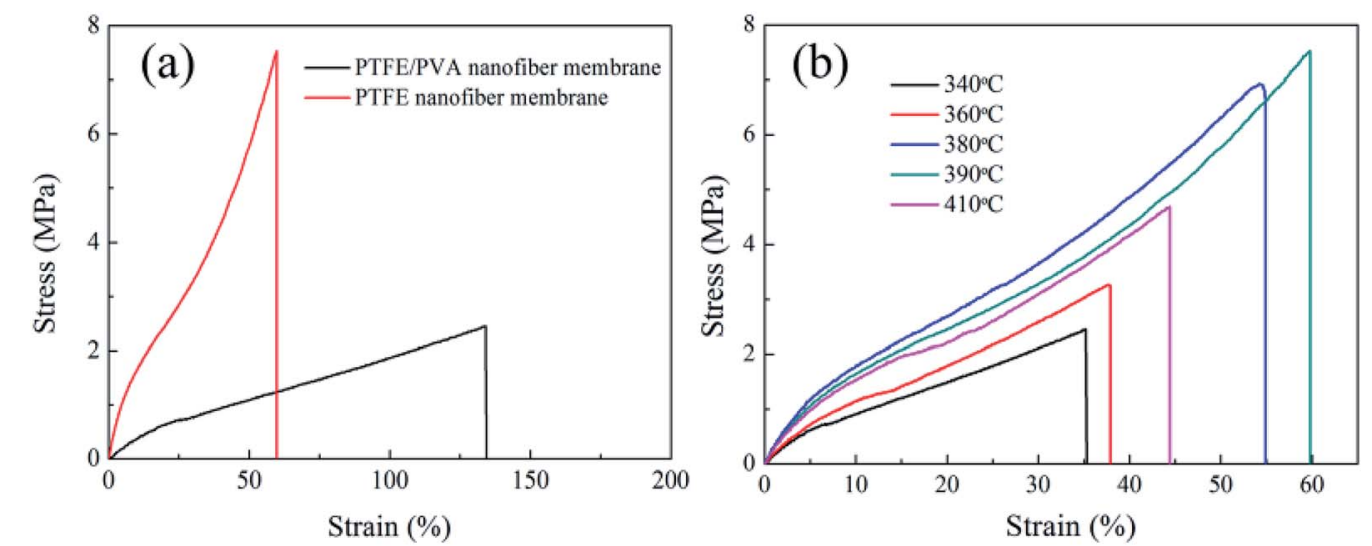

Fig. 13 Stress-strain curves of the PTFE/PVA precursor membranes sintered different temperatures (PTFE/PVA mass ratio was 4 : 1).
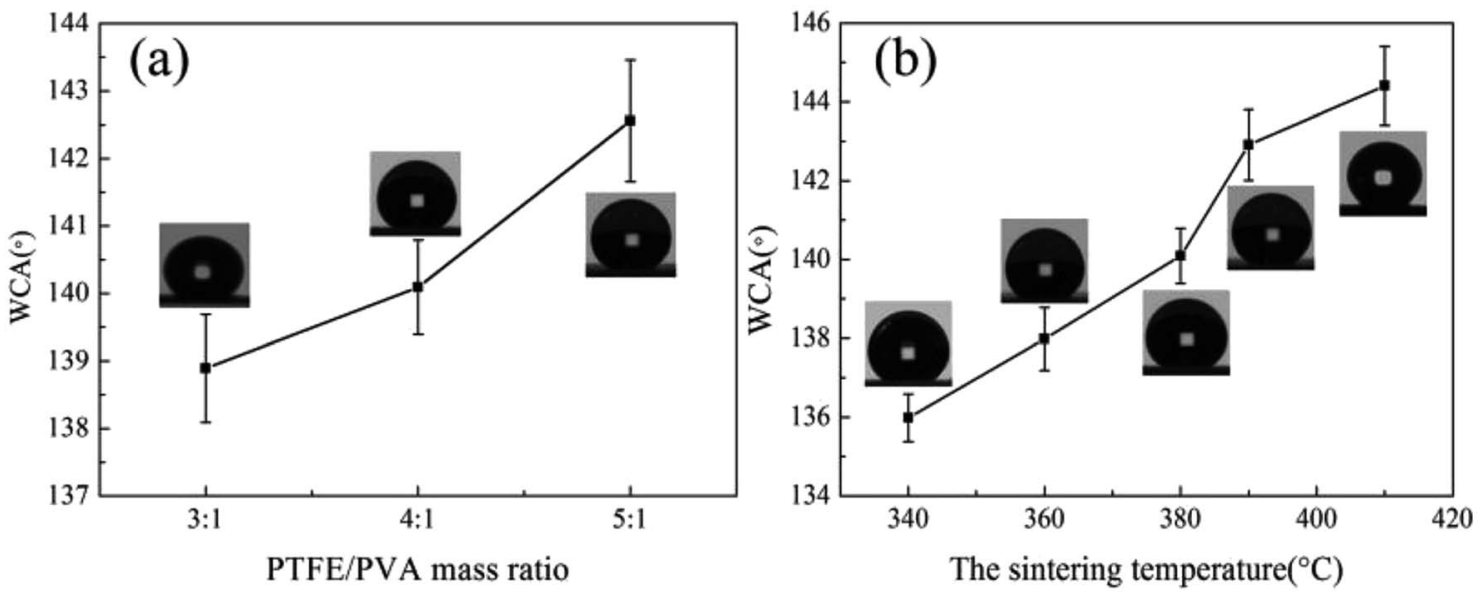

(c)

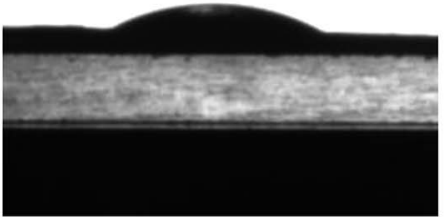

Fig. 14 The water contact angle of PTFE nanofiber membranes (a) different PTFE/PVA mass ratios, sintered at $380{ }^{\circ} \mathrm{C}$; (b) different sintering temperatures, the PTFE/PVA mass ratio was $4: 1$; (c) as-spun composite membrane. 
Table 1 The properties of PTFE nanofiber membranes at different PTFE/PVA mass ratios at a sintering temperature of $380{ }^{\circ} \mathrm{C}$

\begin{tabular}{|c|c|c|c|c|}
\hline Samples & Thickness $(\mu \mathrm{m})$ & Water contact angle $\left(^{\circ}\right)$ & $\begin{array}{l}\text { Mean diameter of } \\
\text { PTFE membranes }(\mu \mathrm{m})\end{array}$ & Porosity (\%) \\
\hline $3: 1$ & $28 \pm 2.0$ & $138.89 \pm 0.8$ & $1.7 \pm 0.03$ & $86.3 \pm 2.5$ \\
\hline $5: 1$ & $32 \pm 1.0$ & $142.56 \pm 0.9$ & $1.97 \pm 0.06$ & $80.6 \pm 3.8$ \\
\hline
\end{tabular}

Table 2 The properties of PTFE nanofiber membranes prepared at different temperatures (the mass ratio of PTFE/PVA was $4: 1$ )

\begin{tabular}{lllll}
\hline & & & Mean pore size of \\
Samples & Thickness $(\mu \mathrm{m})$ & Water contact angle $\left(^{\circ}\right)$ & $1.9 \pm 0.12$ & $78.9 \pm 3.5$ \\
\hline $340^{\circ} \mathrm{C}$ & $25 \pm 1.0$ & $135.98 \pm 0.6$ & $1.85 \pm 0.06$ & $82.3 \pm 2.8$ \\
$360^{\circ} \mathrm{C}$ & $24 \pm 2.0$ & $137.97 \pm 0.8$ & $1.82 \pm 0.08$ & $84.4 \pm 1.3$ \\
$380^{\circ} \mathrm{C}$ & $23 \pm 3.0$ & $140.09 \pm 0.7$ & $1.76 \pm 0.11$ & $86.3 \pm 3.4$ \\
$390^{\circ} \mathrm{C}$ & $23 \pm 2.0$ & $142.91 \pm 0.9$ & & \\
\hline
\end{tabular}

temperature. When the sintering temperatures were $340{ }^{\circ} \mathrm{C}$ and $360{ }^{\circ} \mathrm{C}$, the values of the water contact angle were lower than that of $380{ }^{\circ} \mathrm{C}, 390{ }^{\circ} \mathrm{C}$ and $410{ }^{\circ} \mathrm{C}$ due to the existence of PVA. There was no precise rule to describe the water contact angle increasing tendency. The low surface and the roughness on multiple scales were two important facts to form the hydrophobic surface.

\subsection{The pore size and porosity of the pure nanofiber membranes}

The pore size distribution and pore size of the prepared PTFE nanofiber membrane were measured and the results were presented in Fig. 15, Tables 1 and 2. The PTFE nanofiber membranes had a suitable pore size and a uniform pore size distribution, which was good for high-efficiency fine particulate filtration. As the mass ratio of PTFE/PVA increased from $3: 1$ to $5: 1$, a slight increase was seen in the pore size. The increase in the pore size of relevant membranes could be owing to the increase fiber diameter with increasing the PTFE particles. It could be seen that when the mass ratio of PTFE/PVA reached $6: 1$, the nanofiber membranes were showed to be PTFE resins rather than fibers. For this structure of the precursor membranes, it was difficult for the PTFE particles to fuse together which prevented the formation of an interconnected fibrous network and made the mean pore size of the membranes after sintering larger. Meanwhile, it could be seen that the pore sizes of the PTFE nanofiber membranes decreased with the increase of sintering temperature. The membrane was still shown to fiber assembled, but on the fiber crossover points, the fibers tend to fuse together and led to an interconnected fibrous network. When the sintering temperature was $410{ }^{\circ} \mathrm{C}$, the high temperature might lead to the shrinkage of fibers and junction-formation between fibers. That was why the smaller pore size with higher sintering temperature.

The porosity of the membrane was an important parameter affecting air filtration application. It was well known that the membrane with higher porosity had higher permeate fluxes and lower transmembrane pressure. The porosity of the PTFE nanofiber membrane was shown in Tables 1 and 2 . It could be seen that the membrane porosity kept stable at about $83 \%$. With the increase of the sintering temperature, the porosity increased slightly because of increasing space left by decomposing PVA component and a slight decrease in mean pore size.
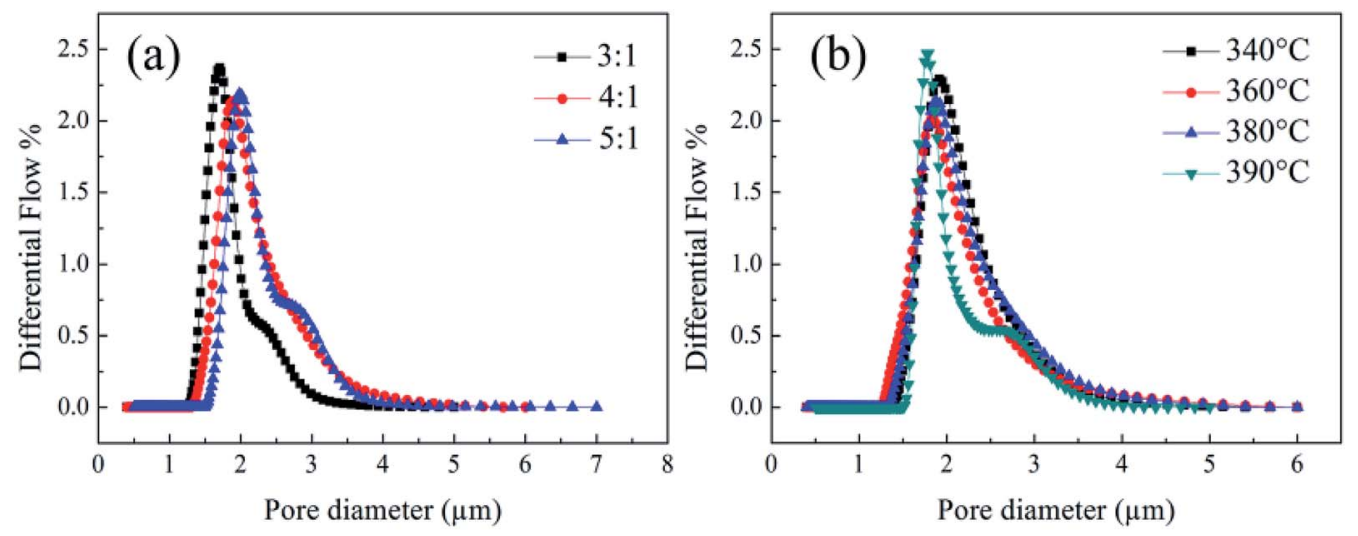

Fig. 15 The pore size of PTFE nanofiber membranes with different (a) PTFE/PVA mass ratios, (sintering temperature: $380{ }^{\circ} \mathrm{C}$ ); (b) sintering temperature (PTFE/PVA mass ratio: $4: 1$ ). 


\subsection{Air purification tests}

3.9.1 Effect of PTFE/PVA mass ration on air filtration. For air filtration materials or air filtration units, filtration efficiency and pressure drop were two important indicators to study the separation behavior of fibrous membranes towards particles, which directly characterize the resistance of fibrous media with different structures to particle mobility. The neutralized $\mathrm{NaCl}$ aerosols were fed into a filter holder and down through the filter with $100 \mathrm{~cm}^{2}$ of effective area. The filtration performance of PTFE nanofiber membranes after sintering at $380{ }^{\circ} \mathrm{C}$ with different PTFE/PVA mass ration under the industrial standard face velocity of $30 \mathrm{~L} \mathrm{~min}{ }^{-1}$ was demonstrated in Fig. 16. Filtration efficiency of nanofibrous mats was dependent on fiber structural properties, especially for fiber diameter and pore size.

As shown in Fig. 16, the filtration efficiency of precursor membranes with different mass ratios that were from $3: 1$ to $5: 1$ after sintering decreased from $98.6789 \%$ to $96.3871 \%$, which could be attributed to the increasing size of average fiber diameter leading to the increased pore size of the membranes. The increase in the pore size was revealed with the increase in fiber diameter, and the maximum pore size value for pure PTFE membranes was obtained from the precursor membranes with the mass ration that was $5: 1$. In case of highly porous membranes flow takes place through shorter and less tortuous path resulting in a smaller air flow pressure drop with high permeability. Interestingly, when the PTFE/PVA mass ratio was $5: 1$, the decrease of filtration efficiency was not obvious, which was due to the increase of roughness and surface area. On the one hand, the increased filtration efficiency of the rough membranes compared with smooth membranes could be contributed to increased projected frontal area constructed. On the other hand, by imposing a pressure gradient across the protrusions modified rough fibers during the filtration generates more streamlined fiber geometry with lower pressure drop compared with smooth membranes, which could be due to the increased stagnation region formed by boundary layers made around the rough fiber. We could conclude that the roughness structure creates higher filtration efficiency and facilitates the penetration of air flow through the membranes, which was important to improve the filtration properties. Meanwhile, the pressure drop of PTFE membranes decreased with increasing the pore size and fiber diameter, which indicated the key role of the mass ratio of PTFE and PVA for decreasing the pressure drop. The QF values of $0.04384,0.04404$ and 0.04236 for the PTFE membranes sintering from the precursor membranes with different mass ratios from $3: 1$ to $5: 1$, confirming the crucial role the widely distributed $2 \mathrm{D}$ nanonets towards the construction of fibrous medium for air filtration, especially for practical applications in the energy saving society.

3.9.2 Effect of sintering temperature on air filtration. The filtration performance of tested PTFE nanofiber membranes in relation to sintering temperature was shown in Fig. 17. It could be seen from Fig. 15 and Table 2 that the pore size decreased with the rise of sintering temperature when the membranes had same PTFE/PVA mass ratio. What was more, the pure nanofiber membranes had similar porosity which kept stable at above $80 \%$ when the sintering temperatures were $340{ }^{\circ} \mathrm{C}, 360{ }^{\circ} \mathrm{C}$, $380{ }^{\circ} \mathrm{C}, 390{ }^{\circ} \mathrm{C}$. The filtration performance of PTFE nanofiber membranes after sintering at different sintering temperatures with the same PTFE/PVA mass ration under the industrial standard face velocity of $30 \mathrm{~L} \mathrm{~min} \min ^{-1}$ was demonstrated in Fig. 17. The filtration efficiency of PTFE nanofiber membranes after sintering at different temperatures increased from $96.7826 \%$ to $98.0560 \%$, which might arise from the fact that the increased sintering temperature thus lead to the decreased pore size of the relevant fibrous membranes. Moreover, the pressure drop of PTFE nanofiber membranes increased from 80.3 Pa to 96.3 $\mathrm{Pa}$ on the basis of the decreased pore size, which indicated the key role of pore structure in regulating the filtration performance.

Interestingly, as shown in Fig. 18, on the membranes after sintering, the abrasion produced many nanowires on the fiber surface which could be owing to that the PTFE dispersing resin produced nanowires under the action of shear force. PTFE nanowire was reported in the study, ${ }^{50}$ which was produced by the abrasion on the fiber surface that benefited to improve the hydrophobicity. It was known that PTFE molecules had a long, straight carbon backbone to which the fluorine atoms were bonded. The electron cloud of the fluorine atoms a uniform helical sheath and such unbranched molecule lead to the high crystallinity. The crystalline form of PTFE changes from a triclinic to a hexagonal lattice at $19^{\circ} \mathrm{C}$. Such transition softens the PTFE particles and then slip of PTFE molecular chain took
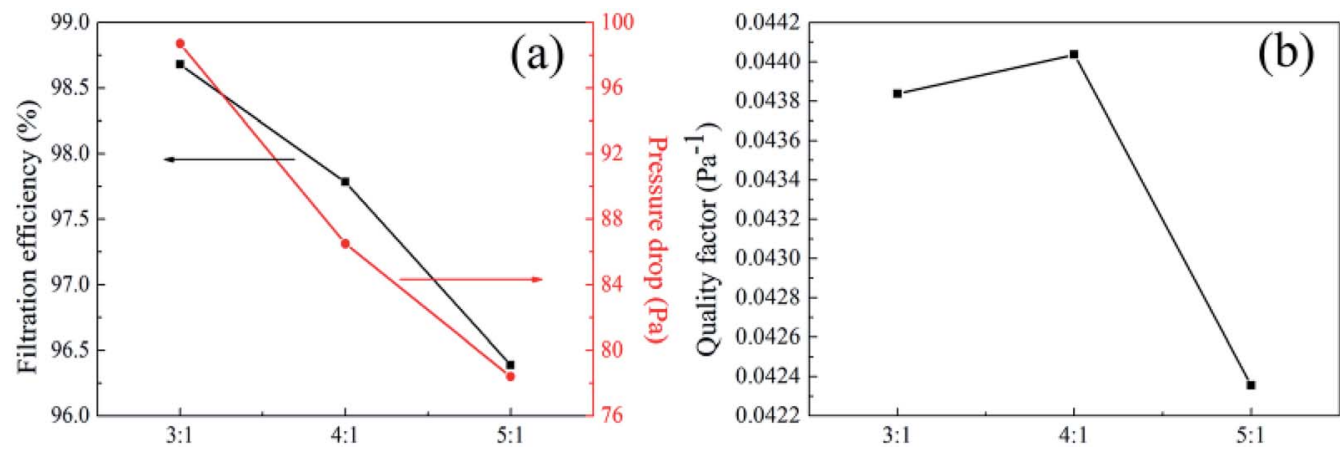

Fig. 16 Filtration performance of PTFE nanofiber membranes with different PTFE/PVA mass ratios (sintered at $380^{\circ} \mathrm{C}$ ) (a) filtration efficiency and pressure drop (b) quality factor values. 

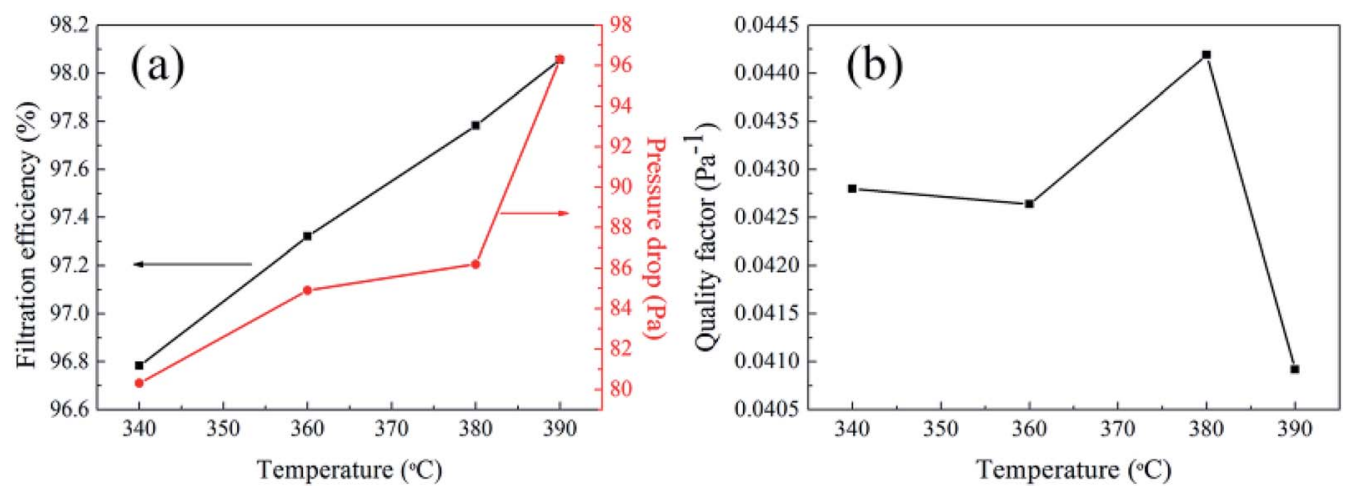

Fig. 17 Filtration performance of PTFE nanofiber membranes with different sintering temperatures (PTFE/PVA mass ratio: $4: 1$ ) (a) filtration efficiency and pressure drop (b) quality factor values.
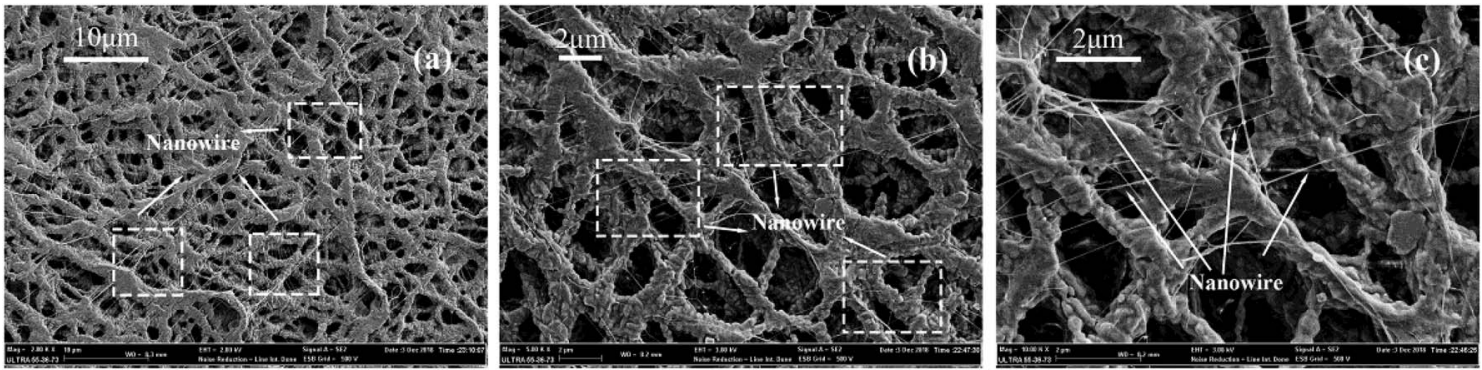

Fig. 18 Morphologies of PTFE nanowire (a) $\times 2000$ surface; (b) $\times 5000$ surface; (c) $\times 10000$ surface.

place under the action of external tension above $19^{\circ} \mathrm{C}$, which results in the formation of fibrils. This structure was a benefit to improve the filtration efficiency but not increase the pressure drop. By considering the high filtration and low pressure drop, when the sintering temperature was $380^{\circ} \mathrm{C}$, the PTFE nanofiber membranes exhibited huge advantages in contrast to other filtration media under the same filtration condition.

3.9.3 Effect of face velocity on air filtration. As could be seen in Fig. 19, the filtration efficiency of these four kinds of membranes sintered at different temperatures showed the same variation behaviors with increasing the face velocity. With an increase in the face velocity, the membranes remained high filtration efficiency and had no obvious change. The PTFE nanofiber membranes exhibited almost no substantive change even at the face velocity of $90 \mathrm{~L} \mathrm{~min}{ }^{-1}$ which was due to the contribution of the nanonet on improving the filtration efficiency based on physical sieving manner, especially under a high face velocity. The curves of pressure drop versus the face velocity were shown in Fig. 19. The pressure drop increased with increasing the face velocity and both of them showed a linear relationship, which was related to that the air flow in the media was typically in low Reynolds number regime, thus the stocks flow regime was considered to prevail in all PTFE membranes.
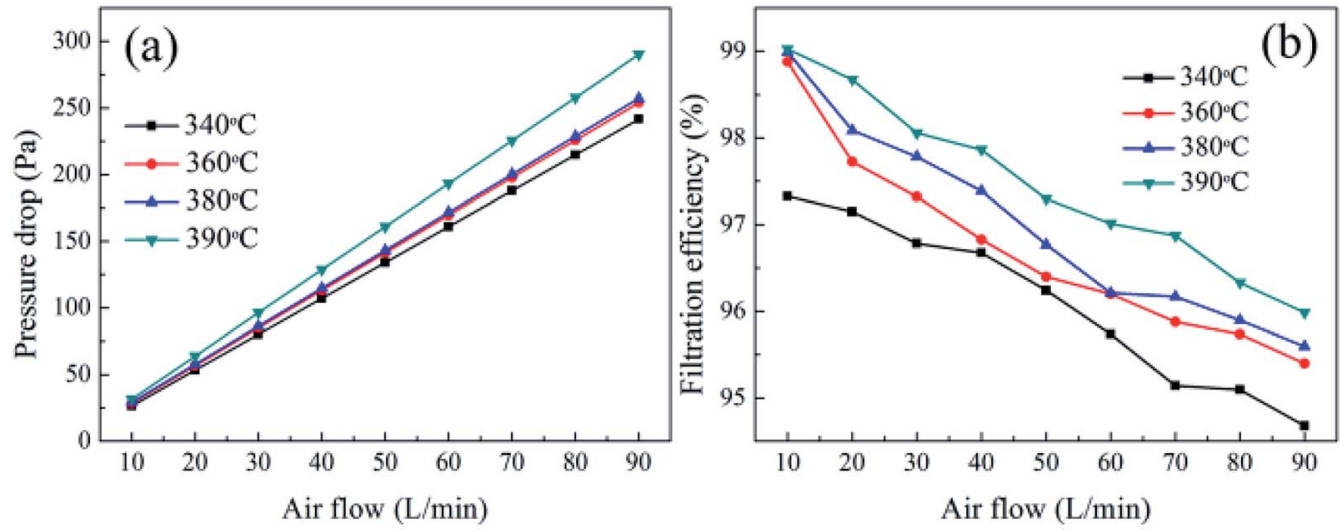

Fig. 19 (a) Pressure drop versus face velocity of the PTFE membranes with different temperatures; (b) filtration efficiency versus face velocity of the PTFE membranes with different temperatures. 


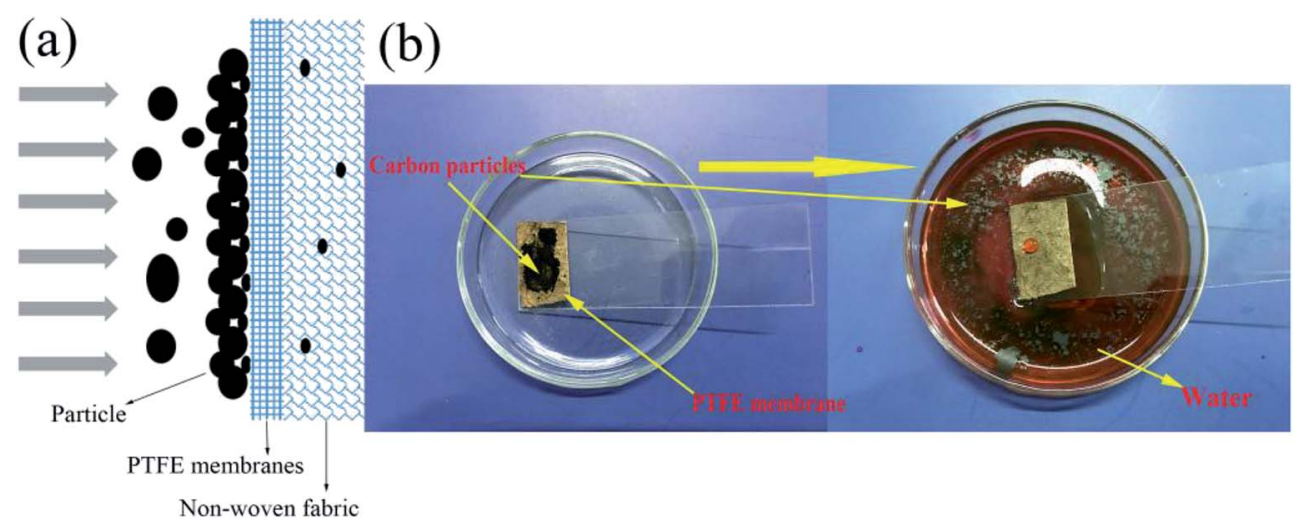

Fig. 20 (a) Simulated the process of surface filtration; (b) simulated the self-cleaning process of the PTFE membranes after filtration.

3.9.4 Repetitive-use performance of filter media. For small particles, the PTFE nanofiber membranes could collect the small particles via direct impaction and Brownian motion and the membranes could remove large particles by surface filtration. Most particles could be collected by surface filtration due to the small pore size. The surface filtration theory was applicable to the case where the particles size of the particles were much larger than the pore size of the filter material, thereby being hindered on the surface of the filter material, allowing only gas to pass. The particles formed a filter cake on the surface of the filter material and continued to exert the filtering effect. The material suitable for the theory was easy to be cleaned, the dust particles were not easy to enter the filter, and the service life was relatively long. Fig. 20(a) and 2 simulated the process of surface filtration.

PTFE had the smallest surface tension in solid materials and did not adhere to any substance. Various cleaning strategies were explored to regenerate the membrane performance after fouling. Water-swilling was adopted to clean the polluted membranes. Fig. 20(b) simulated the process of cleaning the membranes that polluted by carbon particles which could be removed by passing water. This phenomenon showed that the PTFE nanofiber membranes after pollution remained a fine selfcleaning property because of the hydrophobic surface that could protect the structure and performance, showing great potential for applying for high temperature filtration applications.

\section{Conclusions}

In summary, PTFE nanofiber membranes used for air filtration were fabricated by sintering PTFE/PVA/BA electrospun fibrous membranes. The PTFE/PVA mass ratio and the sintering temperature had effects on the morphologies and properties of the membranes. For air filtration, the best performing PTFE nanofiber membranes were made from a PTFE/PVA mass ratio of $4: 1$ and sintered at $380^{\circ} \mathrm{C}$. After sintering, the PTFE nanofiber membranes had the structure of nanofiber and nanowire. The presence of nanowire contributed to improving filtration efficiency. Significantly, the result showed fascinating filtration performances toward $300 \mathrm{~nm}$ sodium chloride aerosol particles at a $30 \mathrm{~L} \mathrm{~min}{ }^{-1}$ airflow velocity in terms of a high filtration efficiency (98\%), relatively low pressure drop (90 Pa). The nanofiber membranes had repetitive-use performances due to the properties of non-sick and hydrophobicity. Because of the high melting point of PTFE nanofiber membranes, this work also provided a versatile strategy for further design and development of functional fibrous membranes for high temperature filtration application.

\section{Conflicts of interest}

There are no conflicts to declare.

\section{Acknowledgements}

This work was supported by the National Natural Science Foundation of China [grant no. 21706238]; Key Laboratory of Advanced Textile Materials and Manufacturing Technology (Zhejiang Sci-Tech University), Ministry of Education (2016QN03), the Excellent Postgraduate Thesis Program of Zhejiang Sci-Tech University (grant no. 2018-XWLWPY-B-03-07, 2018-XWLWPY-M-03-06); Zhejiang Natural Science Foundation Youth Fund Project of China (grant no. LQ19E030022); Zhejiang Public Welfare Technology Application Research Funding Project (grant no. LGF19B060008).

\section{Reference}

1 G. Oberdörster and M. J. Utell, Ultrafine particles in the urban air: to the respiratory tract-and beyond?, Environ. Health Perspect., 2002, 110(8), A440-A441.

2 P. Jamuna, Evaluation of certain food additives. Sixty-ninth report of the Joint FAO/WHO Expert Committee on Food Additives (JECFA). WHO Technical Report Series No. 952. 2009. World Health Organization. Geneva, pages 208, J. Food Sci. Technol., 2010, 47(4), 465-467.

3 X. Querol, A. Alastuey, S. Rodriguez, F. Plana, E. Mantilla and C. R. Ruiz, Monitoring of PM10 and PM2.5 around primary particulate anthropogenic emission sources, Atmos. Environ., 2001, 35(5), 845-858.

4 S. RodríGuez, X. Querol, A. Alastuey, M. A. M. Viana, M. Alarcón, E. Mantilla and C. R. Ruiz, Comparative PM10PM2.5 source contribution study at rural, urban and 
industrial sites during PM episodes in Eastern Spain, Sci. Total Environ., 2004, 328(1), 95-113.

5 Y. P. Li, K. Xiao, J. T. Luo, J. Lee, S. R. Pan and K. S. Lam, A novel size-tunable nanocarrier system for targeted anticancer drug delivery, J. Controlled Release, 2010, 144(3), 314-323.

6 S. Taner, B. Pekey and H. Pekey, Fine particulate matter in the indoor air of barbeque restaurants: Elemental compositions, sources and health risks, Sci. Total Environ., 2013, 454-455, 79-87.

7 R. D. Peng, M. L. Bell, A. S. Geyh, M. D. Aidan, S. L. Zeger, J. M. Samet and D. Francesca, Emergency admissions for cardiovascular and respiratory diseases and the chemical composition of fine particle air pollution, Environ. Health Perspect., 2009, 117(6), 957-963.

8 C. H. Hung and W. F. Leung, Filtration of nano-aerosol using nanofiber filter under low Peclet number and transitional flow regime, Sep. Purif. Technol., 2011, 79(1), 34-42.

9 Y. Liu, B. Cheng, N. Wang, W. Kang, W. Zhang, K. Xing and W. Yang, Development and performance study of polypropylene/polyester bicomponent melt-blowns for filtration, J. Appl. Polym. Sci., 2012, 124(1), 296-301.

10 S. Tanaka, A. Doi, N. Nakatani, Y. Katayama and Y. Miyake, Synthesis of ordered mesoporous carbon films, powders, and fibers by direct triblock-copolymer-templating method using an ethanol/water system, Carbon, 2009, 47(11), 26882698.

11 D. Wang, G. Sun and B. S. Chiou, A High-Throughput, Controllable, and Environmentally Benign Fabrication Process of Thermoplastic Nanofibers, Macromol. Mater. Eng., 2010, 292(4), 407-414.

12 Q. Penghe and M. Chuanbin, Biomimetic branched hollow fibers templated by self-assembled fibrous polyvinylpyrrolidone structures in aqueous solution, ACS Nano, 2010, 4(3), 1573.

$13 \mathrm{~W}$. Xun and L. Yadong, Selected-control hydrothermal synthesis of alpha- and beta- $\mathrm{MnO}(2)$ single crystal nanowires, J. Am. Chem. Soc., 2002, 124(12), 2880-2881.

14 A. Podgórski, A. Bałazy and L. Gradoń, Application of nanofibers to improve the filtration efficiency of the most penetrating aerosol particles in fibrous filters, Chem. Eng. Sci., 2006, 61(20), 6804-6815.

15 V. Thavasi, G. Singh and S. Ramakrishna, Electrospun nanofibers in energy and environmental applications, Energy Environ. Sci., 2008, 1(2), 205-221.

16 R. Balgis, C. W. Kartikowati, T. Ogi, L. Gradon, B. Li, K. Seki and K. Okuyama, Synthesis and evaluation of straight and bead-free nanofibers for improved aerosol filtration, Chem. Eng. Sci., 2015, 137, 947-954.

17 L. Jing, K. Shim, C. Y. Toe, T. Fang, C. Zhao, R. Amal, K. N. Sun, J. H. Kim and Y. H. Ng, Electrospun Polyacrylonitrile-Ionic Liquid Nanofibers for Superior PM2.5 Capture Capacity, ACS Appl. Mater. Interfaces, 2016, 8(11), 7030.

18 K. Liu, Z. Xiao, P. Ma, J. Chen, M. Li, Q. Liu, Y. Wang and D. Wang, Large scale poly(vinyl alcohol-co-ethylene) $/ \mathrm{TiO}_{2}$ hybrid nanofibrous filters with efficient fine particle filtration and repetitive-use performance, $R S C A d v ., 2015$, 5(107), 87924-87931.

19 W. Na, A. Raza, S. Yang, J. Yu, S. Gang and B. Ding, Tortuously structured polyvinyl chloride/polyurethane fibrous membranes for high-efficiency fine particulate filtration, J. Colloid Interface Sci., 2013, 398(19), 240-246.

20 J. Xu, C. Liu, P. C. Hsu, K. Liu, R. Zhang, Y. Liu and Y. Cui, Roll-to-Roll Transfer of Electrospun Nanofiber Film for High-Efficiency Transparent Air Filter, Nano Lett., 2016, 16(2), 1270.

21 S. C. Zhang, H. Liu, J. Y. Yu, W. J. Luo and B. Ding, Microwave structured polyamide-6 nanofiber/net membrane with embedded $\operatorname{poly}(m$-phenylene isophthalamide) staple fibers for effective ultrafine particle filtration, J. Mater. Chem. A, 2016, 4(16), 6149-6157.

22 Y. Y. Zhang, S. Yuan, X. Feng, H. W. Li, J. W. Zhou and B. Wang, Preparation of Nanofibrous Metal-Organic Framework Filters for Efficient Air Pollution Control, J. Am. Chem. Soc., 2016, 138(18), 5785-5788.

23 X. Zhao, S. Wang, X. Yin, J. Yu and B. Ding, Slip-Effect Functional Air Filter for Efficient Purification of PM2.5, Sci. Rep., 2016, 6, 35472.

24 E. N. Brown and D. M. Dattelbaum, The role of crystalline phase on fracture and microstructure evolution of polytetrafluoroethylene (PTFE), Polymer, 2005, 46(9), 30563068.

25 F. Wang, H. Zhu, H. Zhang, H. Tang, J. Chen and Y. Guo, An elastic microporous material with tunable optical property, Mater. Lett., 2016, 164, 376-379.

26 Q. L. Huang, C. F. Xiao, X. Y. Hu and X. F. Li, Study on the effects and properties of hydrophobic poly(tetrafluoroethylene) membrane, Desalination, 2011, 277(1-3), 187-192.

27 T. Kurose, T. Takahashi and K. Koyama, A New Process to Make a Porous PTFE Structure from Aqueous PTFE Dispersion with the Help of Hydrogel, J. Porous Mater., 2004, 11(3), 173-181.

28 S. K. Biswas and K. Vijayan, Friction and wear of PTFE a review, Wear, 1992, 158(1-2), 193-211.

29 S. Meng, Y. Ye, J. Mansouri and V. Chen, Fouling and crystallisation behaviour of superhydrophobic nanocomposite PVDF membranes in direct contact membrane distillation, J. Membr. Sci., 2014, 463(8), 102-112.

30 X. Kang, J. Sun, Y. Mo, F. Zhou, L. Peng, H. Xia, J. Ma and B. Ma, Effect of membrane pore morphology on microfiltration organic fouling: PTFE/PVDF blend membranes compared with PVDF membranes, Desalination, 2014, 343(5), 217-225.

31 Z. Tao, Y. Yao, R. Xiang and Y. Wu, Formation and characterization of polytetrafluoroethylene nanofiber membranes for vacuum membrane distillation, J. Membr. Sci., 2014, 453(453), 402-408.

32 N. Mao, J. X. Liu, D. Q. Chang and X. Sun, Discussion of influencing factors on filtration performances of PTFE membrane filters, Proceedings of the 2015 International Symposium on Computers \& Informatics, 2015, vol. 13, pp. 2274-2281. 
33 N. Zhang, X. Y. Jin, C. Huang and Q. F. Ke, Improved filtration properties of hydroentangled PTFE/PPS fabric filters caused by fibrillation, Indian J. Fibre Text. Res., 2017, 42(3), 278-285.

34 B. H. Park, S. B. Kim, Y. M. Jo and M. H. Lee, Filtration Characteristics of Fine Particulate Matters in a PTFE/Glass Composite Bag Filter, Aerosol Air Qual. Res., 2012, 12(5), 1030-1036.

35 A. Jaworek, A. Krupa and T. Czech, Modern electrostatic devices and methods for exhaust gas cleaning: A brief review, J. Electrostat., 2007, 65(3), 133-155.

36 W. Tanthapanichakoon, M. Hata, K. H. Nitta, M. Furuuchi and Y. Otani, Mechanical degradation of filter polymer materials: Polyphenylene sulfide, Polym. Degrad. Stab., 2006, 91(11), 2614-2621.

37 R. C. Brown and A. Thorpe, Glass-fibre filters with bimodal fibre size distributions, Powder Technol., 2001, 118(1-2), 3-9.

38 H. Leibold, F. Dirks and V. Rüdinger, Particulate emissions from a LLW incinerator and off-gas cleaning with a new type of ceramic candle filter, Waste Manag., 1989, 9(2), 87-94.

39 S. K. Ryi, J. S. Park, S. J. Park, D. G. Lee and S. H. Kim, Fabrication of nickel filter made by uniaxial pressing process for gas purification: Fabrication pressure effect, $J$. Membr. Sci., 2007, 299(1-2), 174-180.

40 X. Wang, J. Gao, J. Zhang, X. Zhang and R. Guo, Theoretical and Experimental Studies on Acetylene Absorption in a Polytetrafluoroethylene Hollow-Fiber Membrane Contactor, Chem. Eng. Technol., 2015, 38(2), 215-222.

41 Y. Takagi, J. C. Lee, S. I. Yagi, H. Yamane, T. Wano, D. Kitagawa and A. E. Salmawy, Fiber making directly from poly(tetrafluoroethylene) emulsion, Polymer, 2011, 52(18), 4099-4105.

42 H. Jue, M. P. Prabhakaran, D. Xin and R. Seeram, Emulsion electrospinning of polycaprolactone: influence of surfactant type towards the scaffold properties, J. Biomater. Sci., Polym. Ed., 2015, 26(1), 57-75.

43 G. Yazgan, A. M. Popa, R. M. Rossi, K. Maniura-Weber, J. Puigmartí-Luis, D. Crespy and G. Fortunato, Tunable release of hydrophilic compounds from hydrophobic nanostructured fibers prepared by emulsion electrospinning, Polymer, 2015, 66, 268-276.

$44 \mathrm{~S}$. Agarwal and A. Greiner, On the way to clean and safe electrospinning-green electrospinning: Emulsion and suspension electrospinning, Polym. Adv. Technol., 2015, 22(3), 372-378.

45 A. L. Yarin, Coaxial electrospinning and emulsion electrospinning of core-shell fibers, Polym. Adv. Technol., 2015, 22(3), 310-317.

46 J. Xiong, P. Huo and F. K. Ko, Fabrication of ultrafine fibrous polytetrafluoroethylene porous membranes by electrospinning, J. Mater. Res., 2011, 24(09), 2755-2761.
47 W. M. Kang, F. Li, Y. X. Zhao, C. M. Qiao, J. G. Ju and B. W. Cheng, Fabrication of porous $\mathrm{Fe}_{2} \mathrm{O}_{3} / \mathrm{PTFE}$ nanofiber membranes and their application as a catalyst for dye degradation, RSC Adv., 2016, 6(39), 32646-32652.

48 W. M. Kang, J. G. Ju, H. S. He, F. Li, L. Q. Tao, Y. C. Dong and B. W. Cheng, Photocatalytic Degradation Performance of $\mathrm{TiO}_{2} /$ PTFE Membrane Catalyst to Methylene Blue, Chem. Lett., 2016, 45(12), 1440-1443.

49 J. F. Su, G. H. Yang, C. L. Cheng, C. Huang, H. Xu and Q. F. Ke, Hierarchically structured $\mathrm{TiO}_{2} / \mathrm{PAN}$ nanofibrous membranes for high-efficiency air filtration and toluene degradation, J. Colloid Interface Sci., 2017, 507, 386-396.

50 Y. Liang, J. Ju, N. Deng, X. Zhou, J. Yan, W. Kang and B. Cheng, Super-hydrophobic self-cleaning bead-like $\mathrm{SiO}_{2} @$ PTFE nanofiber membranes for waterproofbreathable applications, Appl. Surf. Sci., 2018, 442, 54-64.

51 Y. Huang, Q. L. Huang, H. Liu, C. X. Zhang, Y. W. You, N. N. Li and C. F. Xiao, Preparation, characterization, and applications of electrospun ultrafine fibrous PTFE porous membranes, J. Membr. Sci., 2017, 523, 317-326.

52 J. D. Li, Q. Zhong, Y. Y. Yao, S. H. Bi, T. Zhou, X. M. Guo, M. Q. Wu, T. T. Feng and R. L. Xiang, Electrochemical performance and thermal stability of the electrospun PTFE nanofiber separator for lithium-ion batteries, J. Appl. Polym. Sci., 2018, 135(29), 46508.

53 P. Zhao, N. Soin, K. Prashanthi, J. Chen, S. Dong, E. Zhou, Z. Zhu, A. A. Narasimulu, C. D. Montemagno and L. Yu, Emulsion electrospinning of polytetrafluoroethylene (PTFE) nanofibrous membranes for high-performance triboelectric nanogenerators, ACS Appl. Mater. Interfaces, 2018, 10(6), 5880-5891.

54 Y. Huang, C. F. Xiao, Q. L. Huang, H. L. Liu, Z. Guo and K. X. Sun, Robust preparation of tubular PTFE/FEP ultrafine fibers-covered porous membrane by electrospinning for continuous highly effective oil/water separation, J. Membr. Sci., 2018, 568, 87-96.

55 W. Qing, X. Shi, Y. Deng, W. Zhang, J. Wang and C. Y. Tang, Robust superhydrophobic-superoleophilic polytetrafluoroethylene nanofibrous membrane for oil/ water separation, J. Membr. Sci., 2017, 540, 354-361.

56 Y. W. Kai, T. S. Chung and M. Gryta, Hydrophobic PVDF hollow fiber membranes with narrow pore size distribution and ultra-thin skin for the fresh water production through membrane distillation, Chem. Eng. Sci., 2008, 63(9), 25872594.

57 G. Viswanathan, D. B. Kane and P. J. Lipowicz, High Efficiency Fine Particulate Filtration Using Carbon Nanotube Coatings, Adv. Mater., 2010, 16(22), 2045-2049. 